\title{
Matrix Metalloproteinase-3 and Vitamin D Receptor Genetic Polymorphisms, and Their Interactions with Occupational Exposure in Lumbar Disc Degeneration
}

\author{
Han-Yan Yuan ${ }^{1,2}$, Ying Tang ${ }^{1}$, You-Xin Liang $^{1}$, Ling Lei ${ }^{1}$, Guo-Bing XiaO ${ }^{3}$, Sheng Wang ${ }^{4}$ \\ and Zhao-Lin XIA ${ }^{1}$ \\ ${ }^{1}$ Department of Occupational Health, School of Public Health, Fudan University, ${ }^{2}$ Center for Disease Control and \\ Prevention \& Women and Children's Health Care of Gongshu District in Hangzhou, ${ }^{3}$ Ningbo Municipal Institute of \\ Public Health Inspection and ${ }^{4}$ Department of Occupational Health, School of Public Health, Beijing University, \\ China
}

\begin{abstract}
Matrix Metalloproteinase-3 and Vitamin D Receptor Genetic Polymorphisms, and Their Interactions with Occupational Exposure in Lumbar Disc Degeneration: Han-Yan YuAN, et al. Department of Occupational Health, School of Public Health, Fudan University, China-Objectives: To investigate the occupational and genetic risk factors inducing lumbar disc degeneration in a Chinese population, and to explore their synergistic interactions. Methods: A case-control study involving 178 low back pain patients with lumbar disc degeneration and 284 controls was carried out. Five types of work-related factors were investigated using questionnaires. Polymerase chain reaction and restriction fragments length polymorphism was used to detect the polymorphisms of MMP-3 (matrix metalloproteinase-3)(rs731236), VDR-Taq (vitamin D receptor-Taq) and VDR-Apa (vitamin D receptor-Apa)(rs35068180). Rothman's synergy index was used to measure the synergistic interactions between gene polymorphisms and occupational risk factors. Results: Family history of lumbar disc diseases, back injury history, whole-body vibration, bending/twisting, heavy physical workload, age, mutation alleles $5 \mathrm{~A}$ of $M M P-3$ and $A$ of VDR-Apa were significantly associated with lumbar disc degeneration $(\mathrm{OR}=12.70,11.79,8.96,5.46,1.05,1.96$ and 1.70, respectively, $p<0.05)$. Synergistic interactions existed between the mutation allele $5 \mathrm{~A}$ of MMP-3 and wholebody vibration exposure, the mutation allele $5 \mathrm{~A}$ of $M M P$ 3 and bending/twisting, and the mutation allele $A$ of
\end{abstract}

Received Oct 20, 2008; Accepted Oct 28, 2009 Published online in J-STAGE Dec 16, 2009

Correspondence to: Z.-L. Xia, Department of Occupational Health, School of Public Health, Fudan University, 138 Yixueyuan Road, Xuhui District, Shanghai 200032, China (e-mail: zlxia@shmu.edu.cn)
VDR-Apa and bending/twisting ( $\mathrm{SI}=13.27,2.91,2.35$, respectively, $p<0.05)$. Conclusions: The results of this study suggest that gene-occupation interaction might play a certain role in exaggerating lumbar disc degeneration. There is a possibility that subjects who carry mutation alleles $5 \mathrm{~A}$ of MMP-3 and/or A of VDR$A p a$ are more vulnerable to lumbar disc degeneration when they are exposed to whole-body vibration and/or bending/twisting under ergonomic loads.

(J Occup Health 2010; 52: 23-30)

Key words: Gene polymorphism, Lumbar disc degeneration, Occupational risk factors

It is estimated that $15 \%$ to $20 \%$ of adults have back pain during a single year, and $50 \%$ to $80 \%$ experience at least one episode of back pain during their lifetime ${ }^{1)}$. $\mathrm{Jin}^{2)}$ reported that the incidence of low-back pain (LBP) was as high as $50 \%$ in an investigation of one population of Chinese workers. Lumbar disc degeneration is considered to be a primary cause of $\mathrm{LBP}^{3,4}$. The pathogenesis of lumbar disc degeneration includes radial fissures, rim tears in the annulus, and loss of water content in the nucleus pulpous and annulus. These changes are suspected of underlying many back pain symptoms.

The etiology of lumbar disc degeneration is complex, and recent research on the causes of disc degeneration have shed light upon a better understanding of the risk factors contributing to disc degeneration. Magora ${ }^{5)}$ suggested that occupational factors contributing to the acceleration of spinal degeneration included heavy physical loads, manual materials handling consisting of lifting, bending and twisting, prolonged sitting, sustained non-neutral work postures, and vehicle driving. Videman ${ }^{6}$ confirmed that occupational exposures are viewed as the primary source of the mechanical factors 
damaging the spine. This finding was supported by Frymoyer ${ }^{7}$, who found that age, gender, occupation, cigarette smoking, and exposure to vehicular vibration are all associated with the occurrence of LBP. Thus the occupational risk factors mentioned above have remained the focus of recent epidemiologic studies on lumbar disc degeneration.

In contrast, Ala-Kokko's recent studies among families and twins concluded that sciatica, disc herniation, and disc degeneration may be explained to a large degree by genetic factors. As such, the effects of environmental and constitutional risk factors could be relatively minor ${ }^{8)}$. Other relevant studies have supported the idea that degenerative disc disorders may be genetically determined $^{9-12}$. The first gene mutations associated with intervertebral disc degeneration in humans were reported in $1998^{13)}$. That study showed that low MRI signal intensity of thoracic and lumbar discs was associated with TaqI tt genotypes of the vitamin D receptor gene, and a similar MRI pattern was observed for bulging and disc height in both TaqI and FokI genotypes. Subsequent research revealed that a number of genes are associated with disc degeneration in human beings, including an aggrecan gene with shorter numbers of tandem repeat lengths; mutation genes coding for collagen IX (COL 9 $A 2$ and $C O L 9 A 3)$, and the matrix metalloproteinase-3 gene $^{14-17)}$.

Solovieva ${ }^{18)}$ presented evidence suggesting that the effect of obesity on lumbar disc degeneration is modified by COL9A3 gene polymorphisms in Finnish men. These findings indicated that genetic risk factors may interact with environmental factors in exaggerating the development of disc degeneration.

The current study attempted to identify the occupational exposure and genetic risk factors inducing lumbar disc degeneration, and to evaluate their possible synergistic interactions on lumbar disc degeneration in a Chinese population.

\section{Methods}

\section{Subjects}

Using a case-control design, all LBP patients diagnosed as having lumbar disc degeneration were recruited from the outpatient clinics of two local hospitals in one community of Ningbo City, Zhejiang Province between June 2005 and February 2006. The total number of diagnosed lumbar disc degeneration cases was 201, and 178 participated in the current research. During the same enrollment period, 294 controls with no medical history of LBP or lumbar disc degenerative disorders were randomly selected from residents in this community and from among those who visited the same hospitals for a regular medical examination and were diagnosed with no lumbar disc degeneration. Of these 284 controls completed the questionnaire investigation.
All cases had disc degeneration confirmed by undergoing CT (Computed Tomography) examination of the lumbar spine. The degrees of degeneration were evaluated from the CT images by two independent radiologists and an orthopedic spine surgeon, who were not informed about this research. According to a fourpoint scale ${ }^{19}$ ) degeneration was graded as 0 (no signal change), 1 (slight decrease in signal intensity in nucleus pulposus), 2 (distinct decrease in signal intensity in nucleus pulposus with normal disc height), and 3 (severe decrease in signal intensity in nucleus pulposus with disc space narrowing). This scale resulted in a classification of degenerative disorders as non-existent, mild, moderate, and severe, respectively. In the 284 controls, $80.82 \%$ (230) were healthy with no disease, $12.68 \%$ (36) were diagnosed as having normal cardiovascular diseases and $6.50 \%$ (18) were diagnosed as having normal digestive system diseases, which were confirmed to be unconnected with intervertebral disease. The study was approved by the City Ethics Committee. Informed consent was received from all subjects concerned.

\section{Occupational exposure evaluation}

Data regarding individual characteristics were collected by a questionnaire instrument that included items on anthropometric measures. The Body Mass Index (BMI= weight $[\mathrm{kg}]$ per height squared $\left[\mathrm{m}^{2}\right]$ ) was calculated for each subject. Smoking habits, family history of lumbar disc diseases and medical history of back injury were recorded.

A separate questionnaire, developed by the Stockholm Musculoskeletal Intervention Center for assessing manual materials handling, was modified and applied to the assessment of physical and postural loads at work ${ }^{20)}$. Questionnaires were implemented via face-to-face interviews conducted by trained interviewers. Subjects were asked to recall in detail their work history, including descriptions of past jobs, along with the intensity, frequency, and duration of engaging in risk factors that their line of work required. Five potential risk factors for degeneration agreed by US-NIOSH (USA-National Institute for Occupational Safety and Health)—prolonged sitting, whole body vibration, bending/twisting, lifting, and heavy workload-were identified ${ }^{21)}$. Subjects were asked to estimate the number of hours spent per day working under each of the five risk factors. Risk factors were classified into three levels by considering the exposure frequency and employment years: low, moderate and high (Table 1).

\section{Determination of genotypes}

Blood samples were collected intravenously from the 178 cases and 284 controls. Genomic deoxyribonucleic acid (DNA) was extracted from white blood cells according to the procedures of the genomic DNA extraction kit. 
Table 1. Three-level scaled occupational risk factors

\begin{tabular}{|c|c|c|}
\hline Risk factors & Level & Description \\
\hline Prolonged sitting & Low & $\leq 4 \mathrm{~h} /$ day and $<1 \mathrm{yr}$ \\
\hline Bending/twisting & $\begin{array}{l}\text { Moderate } \\
\text { High }\end{array}$ & $\begin{array}{l}\leq 4 \mathrm{~h} / \text { day and } 1-10 \mathrm{yr} \mathrm{OR}>4 \mathrm{~h} / \text { day and } \leq 5 \mathrm{yr} \\
\leq 4 \mathrm{~h} / \text { day and }>10 \mathrm{yr} \mathrm{OR}>4 \mathrm{~h} / \text { day and }>5 \mathrm{yr}\end{array}$ \\
\hline Whole body vibration & Low & $\leq 4 \mathrm{~h} /$ day and $\leq 1 \mathrm{yr}$ \\
\hline Lifting & Moderate & $\leq 4 \mathrm{~h} /$ day and $1-5 \mathrm{yr}$ OR $>4 \mathrm{~h} /$ day and $\leq 2.5 \mathrm{yr}$ \\
\hline Heavy physical workload & High & $\leq 4 \mathrm{~h} /$ day and $>5 \mathrm{yr}$ OR $>4 \mathrm{~h} /$ day and $>2.5 \mathrm{yr}$ \\
\hline
\end{tabular}

Polymerase chain reaction and restriction fragment length polymorphism (PCR-RFLP) methods were applied to detect the polymorphisms of MMP-3 (rs731236) ${ }^{17,22)}$, VDR-Taq, and VDR-Apa (rs35068180) ${ }^{13,23)}$. The primers of MMP-3 were designed as: 5'- GGT TCT CCA TTC CTT TGA TGG GGG GAA AGA -3' and 5' - CTT CCT GGA ATT CAC ATC ACT GCC ACC ACT -3'; and the primers of VDR were designed as: 5' -CAG AGC ATG GAC AGG GAG CAA G-3' and 5'-GCA ACT CCT CAT GGC TGA GGT CTC A-3'. The fragments of MMP-3 digested by the restriction enzyme Tth111Iwere: 6A6A (130 bp), 6A5A (130, 100, $30 \mathrm{bp})$, and 5A5A (100, 30 $\mathrm{bp}) ; 5 \mathrm{~A}$ was the mutation allele. There were two mutated allele sites in the PCR products of VDR, which were recognized and digested by restriction enzymes TaqI and ApaI. The fragments in different sizes of VDR-Taq included TT (495, 245 bp), Tt (495, 245, 290, 205 bp) and $\mathrm{tt}(245,290,205 \mathrm{bp})$; $t$ was the mutation allele. The genotypes of VDR-Apa were AA (740 bp), Aa (740, 520, $220 \mathrm{bp})$ and aa $(520,220 \mathrm{bp})$; A was the mutation allele.

All blood samples were successfully genotyped. The frequency distribution of gene polymorphisms conformed to the Hardy-Weinberg Equilibrium.

\section{Statistical analysis}

The odds ratios (OR) of occupational and genetic risk factors, as estimators of relative risk, and their $95 \%$ confidence intervals (CI) were computed using nonconditional logistic regression. The Chi-squared goodness of fit test was used to check for any deviations from the Hardy-Weinberg Equilibrium.

Interaction between a gene polymorphism $(\mathrm{G})$ and an environmental factor (E) was evaluated using an additive model ${ }^{24)}$. The synergism for the additive scale was measured with a synergy index (SI), which can be calculated by the mathematical formula: $\mathrm{SI}=\left(\mathrm{OR}_{G E}-1\right) /$ $\left(\mathrm{OR}_{\bar{G} E}+\mathrm{OR}_{G \bar{E}}-2\right)$. The $\mathrm{OR}_{G E}$ is a joint effect of factors $\mathrm{G}$ and $\mathrm{E}$, in which the $\mathrm{OR}_{\bar{G}}$ is the main effect caused by factor E only; and $\mathrm{OR}{ }_{G \bar{E}}$ is the main effect by factor $\mathrm{G}$ only. The SI will be 1.0 when there is no interaction between factors $\mathrm{G}$ and $\mathrm{E}$, while a SI value over 1.0 indicates the presence of synergistic interaction, meaning that the joint effect of factors $G$ and $E$ is stronger than the additivity of the single effect. The higher the SI value, the stronger the joint effect will be. A two-tailed U test ${ }^{25)}$ was used to examine the statistical significance of SI, and values of $p \leq 0.05$ were considered to be statistically significant.

\section{Results}

Characteristics of subjects

The characteristics of cases and controls, including age, gender, BMI, smoking, back injury history and family history of disc degeneration, are shown in Table 2.

\section{Environmental risk factors}

In non-conditional logistic analyses, we found that family history of lumbar disc diseases, back injury history, whole-body vibration, bending/twisting, heavy physical workload, and age were associated with lumbar disc degeneration, with statistically significant differences between the case and control groups. The OR value of whole-body vibration reached 8.96 (95\% $\mathrm{CI}=2.47-32.49)$, indicating that people exposed to whole-body vibration at high levels were more likely to develop lumbar disc degeneration than those without exposure. A family history of disc degenerative disease and back injury showed a high risk of lumbar disc degeneration, as demonstrated by the OR values of 9.19 (95\% CI=4.1720.24) and 11.79 (95\% CI=4.40-31.62), respectively. Exercise may be a protective factor for a functioning lumbar spine $(\mathrm{OR}=0.43,[95 \% \mathrm{CI}=0.31-0.59])$ (Table 3).

\section{Effect of MMP-3 and VDR gene polymorphisms on lumbar disc degeneration \\ The frequencies of mutation genotypes $M M P-3$ and $V D R-A p a$ in lumbar disc degeneration cases were significantly higher than those in controls $(\mathrm{OR}=1.96[95 \%$ $\mathrm{CI}=1.33-2.89$ ] and 1.70 [95\% $\mathrm{CI}=1.15-2.51]$, respectively), while no significant difference was observed for the distribution of VDR-Taq variant genotypes (Table 4).}

Synergistic interactions between polymorphisms and occupational exposure

The joint effects of mutation genotypes and 
Table 2. Caracteristics of subjects

\begin{tabular}{|c|c|c|c|c|}
\hline \multicolumn{2}{|l|}{ Variables } & \multirow{2}{*}{$\begin{array}{c}\text { Cases }(178) \\
48.5 \pm 13.1\end{array}$} & \multirow{2}{*}{$\begin{array}{c}\text { Controls (284) } \\
40.6 \pm 15.8\end{array}$} & \multirow{2}{*}{$\frac{p}{<0.05}$} \\
\hline Age $($ mean $\pm S D)$ & & & & \\
\hline \multirow{2}{*}{ Gender } & Male (\%) & $84(47.8)$ & $96(32.7)$ & $<0.05$ \\
\hline & Femal $(\%)$ & $94(52.2)$ & 188 (67.4) & \\
\hline $\mathrm{BMI}($ mean $\pm \mathrm{SD})$ & & $22.8 \pm 2.8$ & $22.5 \pm 3.3$ & $>0.05$ \\
\hline \multirow[t]{2}{*}{ Smoking } & Yes $(\%)$ & $66(37.3)$ & $57(20.1)$ & $<0.05$ \\
\hline & No $(\%)$ & $112(62.7)$ & $127(79.9)$ & \\
\hline \multirow[t]{2}{*}{ Back injury history } & Yes $(\%)$ & $48(26.9)$ & $6(2.0)$ & $<0.05$ \\
\hline & No $(\%)$ & $130(73.1)$ & $278(98.0)$ & \\
\hline \multirow{3}{*}{$\begin{array}{l}\text { Family history of disc } \\
\text { degeneration }\end{array}$} & Yes $(\%)$ & $14(18.4)$ & $7(2.7)$ & $<0.05$ \\
\hline & No $(\%)$ & 164 (71.6) & 277 (97.3) & \\
\hline & $6 \mathrm{~A} 6 \mathrm{~A}(\%)$ & $59(33.15)$ & $140 \quad(49.30)$ & $<0.05$ \\
\hline \multirow[t]{2}{*}{ MMP3 } & $6 \mathrm{~A} 5 \mathrm{~A}(\%)$ & $107(60.11)$ & $126(44.37)$ & $<0.05$ \\
\hline & $5 \mathrm{~A} 5 \mathrm{~A}(\%)$ & $12(6.74)$ & $18(6.34)$ & \\
\hline \multirow[t]{2}{*}{ VDR-Taq } & $\mathrm{TT}(\%)$ & $156(87.64)$ & $256(90.14)$ & $>0.05$ \\
\hline & $\mathrm{Tt}(\%)$ & $22(12.36)$ & $28(9.86)$ & \\
\hline \multirow[t]{3}{*}{ VDR-Apa } & $\mathrm{AA}(\%)$ & $20(11.24)$ & $27(9.51)$ & $<0.05$ \\
\hline & $\mathrm{Aa}(\%)$ & $100(56.18)$ & $129(45.42)$ & \\
\hline & aa $(\%)$ & $58(32.58)$ & 128 (45.07) & \\
\hline
\end{tabular}

Table 3. Non-conditional logistic analyses for risk factors of lumbar disc degeneration

\begin{tabular}{llc}
\hline Factors & OR $(95 \% \mathrm{CI})$ & $p$ \\
\hline Age & $1.05(1.03-1.07)$ & $<0.001$ \\
Family history & $9.19(4.17-20.24)$ & $<0.001$ \\
Injury history & $11.79(4.40-31.62)$ & $<0.001$ \\
Exercise & $0.43(0.31-0.59)$ & $<0.001$ \\
Moderate bending/twisting & $3.54(1.76-7.12)$ & $<0.001$ \\
High bending/twisting & $4.06(2.15-7.65)$ & $<0.001$ \\
Moderate whole-body vibration & $2.71(1.01-7.29)$ & 0.04 \\
High whole-body vibration & $8.96(2.47-32.49)$ & $<0.001$ \\
High heavy physical workload & $5.46(2.86-10.42)$ & $<0.001$ \\
\hline
\end{tabular}

OR=odds ratio, $95 \% \mathrm{CI}=95 \%$ confidence intervals.

Table 4. The association between polymorphisms and lumbar disc degeneration

\begin{tabular}{|c|c|c|c|c|c|c|}
\hline \multicolumn{2}{|c|}{ Genotypes } & \multicolumn{2}{|c|}{ Controls } & \multicolumn{2}{|c|}{ Cases } & \multirow[t]{2}{*}{ OR $(95 \% \mathrm{CI})$} \\
\hline & & $\mathrm{n}$ & $\%$ & $\mathrm{n}$ & $\%$ & \\
\hline \multirow[t]{2}{*}{$M M P-3$} & $6 \mathrm{~A} 6 \mathrm{~A}$ & 140 & 49.30 & 59 & 33.15 & $1.96(1.33-2.89)$ \\
\hline & $6 \mathrm{~A} 5 \mathrm{~A} / 5 \mathrm{~A} 5 \mathrm{~A}$ & 144 & 50.70 & 119 & 66.85 & \\
\hline \multirow[t]{2}{*}{$V D R-T a q$} & $\mathrm{TT}$ & 256 & 90.14 & 156 & 87.64 & $1.29(0.71-2.33)$ \\
\hline & $\mathrm{Tt}$ & 28 & 9.86 & 22 & 12.36 & \\
\hline \multirow[t]{2}{*}{$V D R-A p a$} & aa & 128 & 45.07 & 58 & 32.58 & $1.70(1.15-2.51)$ \\
\hline & $\mathrm{AA} / \mathrm{Aa}$ & 156 & 54.93 & 120 & 67.42 & \\
\hline
\end{tabular}

Adjusted for gender, age, BMI, smoking, family history of disc degeneration and back injury history. 
Table 5. The interaction between gene polymorphisms and occupational exposure (OR, 95\% CI)*

\begin{tabular}{|c|c|c|c|c|c|c|}
\hline \multirow{2}{*}{$\begin{array}{l}\text { Occupational risk } \\
\text { factors }\end{array}$} & \multicolumn{2}{|c|}{$M M P-3$ genotypes } & \multicolumn{2}{|c|}{$V D R$-Apa genotypes } & \multicolumn{2}{|c|}{$V D R-T a q$ genotypes } \\
\hline & $6 \mathrm{~A} 6 \mathrm{~A}$ & $6 \mathrm{~A} 5 \mathrm{~A} / 5 \mathrm{~A} 5 \mathrm{~A}$ & aa & $\mathrm{Aa} / \mathrm{AA}$ & TT & $\mathrm{Tt}$ \\
\hline \multicolumn{7}{|l|}{ lifting } \\
\hline Low level & 1.00 & $\begin{array}{c}2.64 \\
(1.50-4.66)\end{array}$ & 1.00 & $\begin{array}{c}1.50 \\
(0.87-2.58)\end{array}$ & 1.00 & $\begin{array}{c}1.52 \\
(0.68-3.36)\end{array}$ \\
\hline \multirow[t]{2}{*}{ Moderate/High level } & $\begin{array}{c}4.41 \\
(2.08-8.12)\end{array}$ & $\begin{array}{c}7.55 \\
(3.92-14.53)\end{array}$ & $\begin{array}{c}2.61 \\
(1.32-5.17)\end{array}$ & $\begin{array}{c}5.25 \\
(2.84-9.69)\end{array}$ & $\begin{array}{c}3.31 \\
(2.10-5.20)\end{array}$ & $\begin{array}{c}2.98 \\
(1.05-8.49)\end{array}$ \\
\hline & \multicolumn{2}{|c|}{$\begin{array}{l}\mathrm{SI}=1.28, \mathrm{AP}=0.30 \\
\mathrm{u}=1.2706, p>0.05\end{array}$} & \multicolumn{2}{|c|}{$\begin{array}{l}\mathrm{SI}=2.01, \mathrm{AP}=0.41 \\
\mathrm{u}=1.6390, p>0.05\end{array}$} & \multicolumn{2}{|c|}{$\begin{array}{c}\mathrm{SI}=0.70 \\
\mathrm{u}=-0.6672, p>0.05\end{array}$} \\
\hline \multicolumn{7}{|l|}{ Bending/twisting } \\
\hline Low level & 1.00 & $\begin{array}{c}1.76 \\
(0.95-3.28)\end{array}$ & 1.00 & $\begin{array}{c}1.27 \\
(0.69-2.34)\end{array}$ & 1.00 & $\begin{array}{c}1.07 \\
(0.44-2.63)\end{array}$ \\
\hline \multirow[t]{2}{*}{ Moderate/High level } & $\begin{array}{c}3.32 \\
(1.70-6.48)\end{array}$ & $\begin{array}{c}9.95 \\
(5.02-19.04)\end{array}$ & $\begin{array}{c}3.39 \\
(1.88-7.39)\end{array}$ & $\begin{array}{c}7.26 \\
(3.87-13.62)\end{array}$ & $\begin{array}{c}4.49 \\
(2.83-7.13)\end{array}$ & $\begin{array}{c}7.32 \\
(2.64-20.29)\end{array}$ \\
\hline & \multicolumn{2}{|c|}{$\begin{array}{l}\mathrm{SI}=2.91, \mathrm{AP}=0.59 \\
\mathrm{u}=2.3313, p<0.05\end{array}$} & \multicolumn{2}{|c|}{$\begin{array}{l}\mathrm{SI}=2.35, \mathrm{AP}=0.50 \\
\mathrm{u}=2.0022, p<0.05\end{array}$} & \multicolumn{2}{|c|}{$\begin{array}{l}\mathrm{SI}=1.78, \mathrm{AP}=0.38 \\
\mathrm{u}=0.6065, p>0.05\end{array}$} \\
\hline \multicolumn{7}{|c|}{ Heavy physical workload } \\
\hline Low level & 1.00 & $\begin{array}{c}2.55 \\
(1.47-4.43)\end{array}$ & 1.00 & $\begin{array}{c}1.43 \\
(0.85-2.42)\end{array}$ & 1.00 & $\begin{array}{c}0.91 \\
(0.39-2.13)\end{array}$ \\
\hline \multirow[t]{2}{*}{ Moderate/High level } & $\begin{array}{c}7.24 \\
(3.39-15.44)\end{array}$ & $\begin{array}{c}11.48 \\
(5.70-23.11)\end{array}$ & $\begin{array}{c}4.86 \\
(2.27-10.42)\end{array}$ & $\begin{array}{c}7.76 \\
(4.05-14.88)\end{array}$ & $\begin{array}{c}4.96 \\
(2.96-8.32)\end{array}$ & $\begin{array}{c}9.96 \\
(2.69-36.90)\end{array}$ \\
\hline & \multicolumn{2}{|c|}{$\begin{array}{c}\mathrm{SI}=1.35, \mathrm{AP}^{\#}=0.27 \\
\mathrm{u}=0.6746, p>0.05\end{array}$} & \multicolumn{2}{|c|}{$\begin{array}{l}\mathrm{SI}=1.58, \mathrm{AP}=0.32 \\
\mathrm{u}=1.3033, p>0.05\end{array}$} & \multicolumn{2}{|c|}{$\begin{array}{l}\mathrm{SI}=2.32, \mathrm{AP}=0.51 \\
\mathrm{u}=0.8317, p>0.05\end{array}$} \\
\hline \multicolumn{7}{|l|}{ Whole-body vibration } \\
\hline Low level & 1.00 & $\begin{array}{c}1.75 \\
(1.13-2.71)\end{array}$ & 1.00 & $\begin{array}{c}1.57 \\
(1.01-2.44)\end{array}$ & 1.00 & $\begin{array}{c}1.27 \\
(0.66-2.47)\end{array}$ \\
\hline \multirow[t]{2}{*}{ Moderate/High level } & $\begin{array}{c}1.89 \\
(1.27-2.98)\end{array}$ & $\begin{array}{c}9.49 \\
(3.57-25.23)\end{array}$ & $\begin{array}{c}2.20 \\
(0.68-7.15)\end{array}$ & $\begin{array}{c}3.96 \\
(1.77-8.88)\end{array}$ & $\begin{array}{c}2.58 \\
(1.31-5.08)\end{array}$ & $\begin{array}{c}3.90 \\
(0.35-48.86)\end{array}$ \\
\hline & \multicolumn{2}{|c|}{$\begin{array}{c}\mathrm{SI}=13.27, \mathrm{AP}=0.72 \\
\mathrm{u}=1.9735, p<0.05\end{array}$} & \multicolumn{2}{|c|}{$\begin{array}{l}\mathrm{SI}=1.67, \mathrm{AP}=0.30 \\
\mathrm{u}=0.9988, p>0.05\end{array}$} & \multicolumn{2}{|c|}{$\begin{array}{l}\mathrm{SI}=1.57, \mathrm{AP}=0.27 \\
\mathrm{u}=0.4932, p>0.05\end{array}$} \\
\hline
\end{tabular}

*: Adjusted for gender, age, BMI, smoking, family history of disc degeneration and back injury history. \#: Attributable Proportion (AP) is the proportion that the synergistic effect could explain.

occupational exposure on lumbar disc degeneration are presented in Table 5. Two mutation alleles (5A of $M M P$ 3 and $\mathrm{A}$ of $V D R-A p a)$ and bending/twisting acted synergistically to increase the risk of lumbar disc degeneration ( $\mathrm{SI}=2.91$ and 2.35 , respectively, $p<0.05$ ). Additionally, the synergistic interaction between mutation allele 5A of $M M P-3$ and whole-body vibration made the risk of lumbar disc degeneration much higher than each factor acting alone $(\mathrm{SI}=13.27, p<0.05)$. The synergistic interactions between mutation genotypes were also analyzed, but there were not statistically significant (not shown in Table 5).

\section{Discussion}

The OR value associated with age was $1.05(p<0.05)$ by non-conditional logistic analyses, suggesting an increased tendency to develop disc degeneration with age. A previous study showed an increased prevalence of disc degeneration from $16 \%$ at age 20 to about $98 \%$ at age 70 , based on macroscopic disc degeneration grades of 600 autopsy specimens ${ }^{26)}$. Some researchers have pointed out that lumbar disc degeneration may start from the age of 20, and the flexibility of the lumbar disc reduces as age increases ${ }^{27,28)}$. Early degenerative changes in the mature disc are characterized by loss of water content in the nucleus pulpous and annular tears, which are commonly associated with disc space narrowing. The degeneration develops with increasing age, and the stability of the motion segment may be compromised eventually. 
The OR of back injury history in the present research was 11.79 , showing a strong association with disc degeneration. This finding may in part be interpreted by the theory of accident-related trauma, which posits that structural lesions of the disc will lead to "degenerative" changes. Subjects with family history of lumbar disc diseases demonstrated an increased risk of suffering from lumbar disc degeneration. This indicates that familial susceptibility is a contributing factor to degeneration, and that lumbar disc degeneration may be genetically determined.

The three work-related risk factors of whole-body vibration, bending/twisting, and heavy physical workload were associated with lumbar disc degeneration. Individuals exposed to high levels of whole-body vibration were approximately eight times more likely to suffer from lumbar disc degeneration, compared to those who were unexposed. Prolonged sitting and lifting, however, were not significantly associated with disc degeneration. This result is similar to Lawrence's findings, in which lumbar disc degeneration was more common in male workers with physically demanding tasks than those who were more sedentary ${ }^{29}$. Furthermore, Farfan ${ }^{30)}$ suggested that bending/twisting was the main cause of disc damage. Thus, the effects of occupational factors seem to depend on the combination of their frequency, intensity, and duration. As the occupational factor becomes stronger, it is likely to damage the structure of the lumbar disc by narrowing the disc space and breaking annular fibrosis, and by gradually destroying the function of the musculoskeletal system. Earlier experiments have indicated that vibration may affect the metabolism of the disc cell matrix and nutrition supply, exacerbating the lumbar disc pressure, energy consumption, and water loss from nucleus pulposus and annular tears ${ }^{31)}$.

For genetic risk factors, the results of this study showed a significantly higher frequency of $V D R$ and $M M P-3$ mutation genotypes in lumbar disc degeneration patients relative to controls. Mutation genotype tt of VDR-Taq was the first genetic risk factor associated with intervertebral disc degeneration in humans ${ }^{13)}$. However, tt genotype was found in this study, and there was no significant difference for the distribution of VDR-Taq variant genotypes between cases and controls. The most likely explanation for this finding may lie in the fact that the tt genotype seldom exists in Chinese populations. In one study involving 804 subjects in China, for example, only one single subject carried the tt genotype ${ }^{32}$. In contrast, AA and Aa genotypes of VDR-Apa showed a significant effect on disc degeneration $(\mathrm{OR}=1.70)$, indicating that the VDR-Apa gene polymorphism is one of the genetic risk factors involved in lumbar disc degeneration. A possible mechanism for the action of this polymorphism may depend on the role of the vitamin
D receptor within chondrocytes. The vitamin D receptor binds to the active form of vitamin $\mathrm{D}$ and helps to control the calcium balance, and may additionally act in the differentiation, proliferation, and maturation of chondrocytes. It has been confirmed that chondrocytes play a role in influencing the proteoglycan synthesis in vitro and moreover, that there is a rich presence of chondrocytes and proteoglycans in the lumbar disc ${ }^{33)}$. As a result, vitamin $\mathrm{D}$ receptor polymorphism may be involved in lumbar disc degeneration indirectly, through its function within the chondrocyte. The exact mechanism of action, however, requires further investigation.

It is evident that matrix metalloproteinases (MMPs) and tissue inhibitor of metalloproteinases (TIMPs) regulate the equilibrium of extracellular matrix degradation. Stromelysin (MMP-3) can degrade collagens and also break down other structural components such as proteoglycan and fibronectin ${ }^{33)}$. The expression of MMP-3 is primarily regulated at the level of its transcription. There is a common variant in the promoter sequence of the MMP-3 gene, in which one allele has six adenosines (6A) while the other has only five (5A). Compared with other genotypes, individuals homozygous for the 6A allele will have lower MMP3 levels in their tissues because of reduced gene transcription, and the 5A5A and 5A6A genotypes of $M M P-3$ were associated with more degenerative findings in the elderly than the 6A6A genotype ${ }^{17}$. A similar phenomenon was observed in the present study. The frequencies of 5A5A and 5A6A genotypes of MMP-3 in lumbar disc degeneration cases were significantly higher than those in the controls. The fact that $M M P-3$ has the ability to degrade various connective matrix components, and activate other MMPs, shows that the mutation of MMP-3 may disturb the extracellular matrix balance in the lumbar disc and promote its degeneration.

Soloviea ${ }^{18}$ found that people carrying the trp3 allele of COL9A3 were at greater risk of disc degeneration if they were persistently obese. In our study, obesity did not appear to be a risk factor, because the distribution of BMI was the same in the case and control groups. However, we observed a synergistic interaction between the mutation allele $5 \mathrm{~A}$ of $M M P-3$ and whole-body vibration exposure, the mutation allele $5 \mathrm{~A}$ of $M M P-3$ and bending/twisting, and the mutation allele A of VDR-Apa and whole-body vibration exposure. Simultaneous presence of mutation alleles $5 \mathrm{~A}$ of $M M P-3$ and/or A of VDR-Apa and whole-body vibration and/or bending/ twisting exposure increased the risk of lumbar disc degeneration about three to five times. This finding assumes that mechanical stress coupled with metabolic imbalance mediated by gene polymorphisms accelerates the disc structural damage leading to disc degeneration. The exact mechanism for this action, however, needs to be further researched. 
In the current research, we focused on synergistic interactions between gene polymorphisms and occupational risk factors affecting lumbar disc degeneration, which may be a more reasonable interpretation of the causes of lumbar disc degeneration in Chinese people. The size of the study sample was not large enough to predict the synergic effect of geneenvironment interaction with conclusive accuracy. Follow-up studies with larger sample sizes need to be conducted. Also, we will continue to investigate other gene polymorphisms (COL 9 A2, COL $9 A 3$ and aggrecan gene) to look for the potential causes of disc degeneration. In the multiple comparisons applied to the measure of synergistic interactions, there may have been some statistically bias which will need to be reduced in our future research.

\section{Conclusion}

The results of the present study provide some evidence of gene-environmental interaction on lumbar disc degeneration in Chinese people. Our findings suggest the possibility that subjects carrying mutation alleles $5 \mathrm{~A}$ of $M M P-3$ and/or A of $V D R-A p a$ are more vulnerable to lumbar disc degeneration when exposed to whole-body vibration and/or bending/twisting. Workers carrying mutation alleles 5A of $M M P-3$ and/or A of VDR-Apa should avoid work involving whole-body vibration exposure and/or bending/twisting ergonomic loads in order to reduce the risk of suffering from lumbar disc degeneration.

Acknowledgment: This study was supported by the National Natural Science Foundation of China (NSFC 30471438), project 2006BAI06B08 from Ministry of Science and Technology, and grants 08GWD12, 08GWZX0402 from the Shanghai Bureau of Public Health.

\section{References}

1) Rubin DI. Epidemiology and risk factors for spine pain. Neurol Clin 2007; 25: 353-71.

2) Jin K, Sorock GS, Courtney TK. Prevalence of low back pain in three occupational groups in Shanghai, People's Republic of China. J Safety Res 2004; 35: 23-8.

3) Luoma K, Riihimaki H, Luukkonen R, et al. Low back pain in relation to lumbar disc degeneration. Spine 2000; 25: 487-92.

4) Borenstein DG. Epidemiology, etiology, diagnostic evaluation, and treatment of low back pain. Curr Opin Rheumatol 2001; 13: 128-34.

5) Magora A. Investigation of the relation between low back pain and occupation: IV. Physical requirements: Bending, rotation, reaching, and sudden maximal effort. Scand J Rehabil Med 1973; 5: 189-90.

6) Videman T, Battie MC. Spine update: The influence of occupation on lumbar degeneration. Spine 1999; 24: 1164-70.

7) Frymoyer JW. Lumbar disk disease: Epidemiology. Instr Course Lect 1992; 41: 217-23.

8) Ala-Kokko L. Genetic risk factors for lumbar disc disease. Ann Med 2002; 34: 42-7.

9) Gunzburg R, Fraiser RD, Fraser GA. Lumbar intervertebral disc prolapse in teenage twins: A case report and review of the literature. J Bone Joint Surgery UK 1990; 180: 503-7.

10) Varlotta GP, Brown MD, Kelsey JL, et al. Familial predisposition for herniation of a lumbar disc in patients who are less than twenty-one years old. J Bone Joint Surg USA 1991; 73: 124-8.

11) Simmons Jr ED, Guntupalli M, Kowalski JM, et al. Familial predisposition for degenerative disc disease: A case-control study. Spine 1996; 21: 1527-9.

12) Richardson JK, Chung T, Schultz JS, et al. A familial predisposition toward lumbar disc injury. Spine 1997; 22: $1487-92$.

13) Videman T, Leppavuori J, Kaprio J, et al. Intragenic polymorphisms of the vitamin $\mathrm{D}$ receptor gene associated with intervertebral disc degeneration. Spine 1998; 23: 2477-85.

14) Kawaguchi Y, Osada R, Kanamori M, et al. Association between an aggrecan gene polymorphism and lumbar disc degeneration. Spine 1999; 24: 2456-60.

15) Annune S, Paassilta P, Lohivina J, et al. An allele of COL9A2 associated with intervertebral disc disease. Science 1999; 285: 409-12.

16) Perala M, Raina SS, Karppinen J, et al. Identification of a novel common genetic risk factor for lumbar disk disease. JAMA 2001; 14: 285.

17) Takahashi M, Haro H, Wakabayashi Y, et al. The association of degeneration of the intervertebral disc with $5 \mathrm{a} / 6 \mathrm{a}$ polymorphism in the promoter of the human matrixmetalloproteinase-3 gene. J Bone Joint Surg Br 2001; 83: 491-5.

18) Solovieva S, Lohiniva J, Leino-Arjas P, et al. COL9A3 gene polymorphism and obesity in intervertebral disc degeneration of the lumbar spine: Evidence of geneenvironment interaction. Spine 2002; 27: 2691-6.

19) Kettler A, Rohlmann F, Neidlinger Wilke C, et al. Validity and interobserver agreement of a new radiographic grading system for intervertebral disc degeneration: Part II. Cervical spine. Eur Spine J 2006; 15: 732-41.

20) Wiktorin C, Hjelm EW, Winkel J, et al. Reproducibility of a questionnaire for assessment of physical load during work and leisure time. Stockholm MUSIC I Study Group. MUSculoskeletal Intervention Center. J Occup Environ Med 1996; 38: 190-201.

21) NIOSH. National occupational research agenda for musculoskeletal disorders, DHHS (NIOSH) Publication No. 2001-117. Cincinnati: DHHS, NIOSH; 2001.

22) Fang SM, Jin X, Li Y, et al. Correlation of matrix metalloproteinase-3 polymorphism to genetic susceptibility and lymph node metastasis of non-small cell lung cancer. Chinese J Cancer 2005; 24: 305-10. 
23) Wang S, Liu J, Hu S, et al. Association of vitamin D receptor gene polymorphisms with calcium oxalate calculus disease. J Huazhong University of Science and Technology Med Sci 2003; 23: 38-41.

24) Rothman KJ, Greenland S. Modern Epidemiology, 2nd ed[M]. New York: Lippincott-Raven Publishers; 1998. p.269-273.

25) Rongsheng L. Principle and Method of Epidemiology. Chengdu: Publishing House of Sichuang University; 2005 (in Chinese).

26) Miller JA, Schmatz C, Schultz AB. Lumbar disc degeneration: correlation with prospective study. Br J Sports Med 1989; 3: 150-4.

27) Adams MA, Dolan P, et al. "Stress" distributions inside interverterbral discs. The effects of age and degeneration. J Bone Joint Br 1996; 78: 965-72.
28) Buckwalter JA. Aging and degeneration of the human intervertebral disc. Spine 1995; 20: 1307-14.

29) Lawrence JS. Rheumatism in miners: III. Occupational factors. Br J Industr Med 1955; 12: 249-61.

30) Hf F. Mechanical disorders of the low back. In: Philadelphia: Lea \& Febiger. London: Henry Kimpton Publishers; 1973.

31) Holm S, Nachemson A, et al. Nutrition of the intervertebral disc: Effects induced by vibration. Orthop Transact 1985; 9: 451.

32) Cheung KM, Chan D, Karppine J, et al. Association of the Taq I allele in vitamin D receptor with degenerative disc disease and disc bulge in a Chinese population. Spine 2006; 31: 1143-8.

33) Yupigu H. Hernia of intervertebral discs. Beijing: People's Medical Publishing House; 2004 (in Chinese). 